\title{
Quantification of the relative contribution of estrogen to bone mineral density in men and women
}

Lan T Ho-Pham ${ }^{1,2^{*}}$, Nguyen D Nguyen ${ }^{3}$ and Tuan V Nguyen $3,4,5$

\begin{abstract}
Background: The study quantified the relative contributions of estrogen (E2) and total testosterone (TT) to variation in bone mineral density in men and women.

Methods: This was a cross-sectional study which involved 200 men and 415 women aged 18 to 89 years. BMD at the lumbar spine (LS) and femoral neck (FN) was measured by DXA. Serum levels of E2 and TT were measured by electrochemiluminescence immunoassays. The association between $\mathrm{E} 2, \pi$, and BMD was analyzed by the multiple linear regression model, adjusting for age and BMI. The contribution of each hormone to the variation in BMD was quantified by the bootstrap method.

Results: In women, higher serum levels of $\mathrm{E} 2$, but not $\Pi$, were significantly associated with greater $\mathrm{BMD}$ at the $\mathrm{FN}$ $(P=0.001)$ and $L S(P<0.0001)$. In men, higher serum levels of $E 2$ were independently associated with greater FNBMD $(P=0.008)$ and LSBMD $(P=0.086)$. In the multiple linear regression model, age, body weight and E2 accounted for $50-55 \%$ variance in FNBMD, and $25 \%$ (in men) and $48 \%$ (in women) variance in LSBMD. Variation in E2 accounted for 2.5\% (95\% Cl $0.4-7.8 \%)$ and $11.3 \%$ (95\% Cl $8.1-15.3 \%)$ variation in FNBMD in men and women, respectively. Moreover, E2 contributed 1.2\% (95\% Cl $0.1-5.8 \%)$ and $11.7 \%$ (95\% Cl $8.5-15.9 \%)$ variation in LSBMD in men and women, respectively.
\end{abstract}

Conclusions: Estrogen is more important than testosterone in the determination of age-related bone mineral density men and women of Vietnamese background. However, the relative contributions of estrogen to bone mineral density in men are likely modest.

Keywords: Estradiol, Testosterone, Bone mineral density, Osteoporosis, Men

\section{Background}

That estrogen plays a critical role in bone health in women is a well-known fact. Deficiency of estrogen leads to increased bone loss, lower bone mineral density (BMD), and increased fracture risk [1]. In women with reduced bone density and/or an existing fracture, treatment with estrogen could reduce bone loss, and lower fracture risk [2]. Thus, the BMD-mediated causal relationship between estrogen and fracture in women has been well established.

\footnotetext{
* Correspondence: thuclanhopham@pnt.edu.vn

'Department of Internal Medicine, Pham Ngoc Thach University of Medicine, Thanh Thai Street, District 10, Ho Chi Minh City, Vietnam

²Department of Rheumatology, People's Hospital 115, Ho Chi Minh City, Vietnam

Full list of author information is available at the end of the article
}

However, recently emerging evidence has suggested that estrogen also has important effects on bone health in men. Almost 20 years ago, Smith and colleagues reported a 28year old man with a bone age of 15 years, who had estrogen resistance due to disruptive mutation of the estrogen receptor gene [3]. The man had normal level of testosterone and elevated estradiol, but had severe osteopenia associated with increased values of bone turnover markers. Subsequently, two young men with undetectable estradiol levels due to mutation in the CYP19A1 gene (this gene is responsible for converting androgens to estrogens) were identified $[4,5]$. The two men also had low bone density as initially reported by Smith et al.; however, when the men were treated with estrogen, their BMD increased. These cases have demonstrated that estrogen does play an important role in the
C Biomed Central 
skeletal maturation and mineralization in men, and changes the traditional view that estrogen is a "female hormone".

A series of subsequent case reports have indicated that estrogen is essential for the normal growth and maturation of the skeleton in men with aromatase deficiency and low serum estradiol (E2) levels [4-7]. Some cross-sectional studies have further demonstrated a significant positive relationship between serum E levels and BMD in men [8-14]. Most of these studies were based on elderly populations of Caucasian background, and as a result, it is difficult to assess the relative contribution of estrogen to the interindividual variation in BMD in the general population.

Although these studies collectively suggest that estrogen might be an important factor for bone growth and bone maintenance in men, most studies have not considered the simultaneous effects of estrogen and testosterone on $\mathrm{BMD}$ in men. The question of interest is therefore: what is the proportion of variation in BMD among men and women of Asian background that can be attributed to the variations in estrogen and testosterone. The present study was designed to address that research question by analyzing the relative contributions of serum levels of estradiol and testosterone to the variation in BMD in Asian men and women.

\section{Methods}

\section{Study design and participants}

The study was designed as a cross-sectional investigation, with the setting being Ho Chi Minh City, a major city in Vietnam. The research protocol and procedures were approved by the Scientific Committee of the People's Hospital 115 and Pham Ngoc Thach University of Medicine. All volunteer participants were provided with full information about the study's procedures and aims, and gave informed consent to participate in the study, according to the principles of medical ethics of the World Health Organization and the Helsinki Declaration.

We used simple random sampling technique to identify potential participants. We approached community organizations, including churches and temples, and obtained the list of members, and then randomly selected individuals aged 18 or above. We sent a letter of invitation to the selected individuals. The participants received a free health check-up, and results of lipid analysis, but did not receive any financial incentive. Participants were excluded from the study if they had diseases deemed to affect to bone metabolism, such as hyperthyroidism, hyperparathyroidism, chronic kidney disease, malabsorption syndrome, alcoholism, chronic colitis, multiple myeloma, leukemia or chronic arthritis.

\section{Measurements and data collection}

Data collection was done by research doctors and nurses using a validated questionnaire. The questionnaire solicites the following information from participants: anthropometric factors, lifestyle factors, dietary intakes, physical activity, and clinical history. Anthropometric parameters including age, weight, standing height were obtained. Age was calculated from the date of birth to the date of interview. Height without shoes (in centimeters) was measured to the nearest $0.1 \mathrm{~cm}$ by a wall-mounted stadiometer. Weight, without shoes or clothing, was measured (to the nearest $0.1 \mathrm{~kg}$ ) on an electronic scale. Body mass index (BMI) was then derived as the ratio of weight $(\mathrm{kg})$ over height squared (in $\mathrm{m}^{2}$ ).

\section{Bone mineral density}

Areal BMD was measured at the lumbar spine (L2-L4), femoral neck, and whole body using a Hologic QDR 4500 (Hologic Corp, Madison, WI, USA). The short-term in vivo expressed as the coefficient of variation was $1.8 \%$ for the lumbar spine and $1.5 \%$ for the hip. The machine was standardized by a standard phantom before each measurement. BMD at femoral neck was used as a main variable for analysis.

\section{Measurement of sex hormones}

Blood samples were collected between 8 AM and 10 AM after an overnight fast. Serum concentrations of total testosterone (TT) and estradiol (E2) were measured by electrochemiluminescence immunoassay (ECLIA) on an Roche Elecsys 10100/201 system (Roche Diagnosis Elecsys). This method can measure the concentration of estradiol in the range of 5-4,300 $\mathrm{pg} / \mathrm{ml}(18.4-15781 \mathrm{pmol} / \mathrm{L})$, and total testosterone in the range of $25-15,000 \mathrm{pg} / \mathrm{ml}(87-52000$ $\mathrm{pmol} / \mathrm{L})$. The sensitivity of the assay is $2.18 \mathrm{pg} / \mathrm{ml}$ with an intraassay CV of $6.2 \%$ at $34.8 \mathrm{pg} / \mathrm{ml}$ and $2.8 \%$ at $1018 \mathrm{pg} /$ $\mathrm{ml}$. The inter-assay CV at these two levels was $<20 \%$.

\section{Data analysis}

The association between TT, E2, and BMD was analyzed by the multiple linear regression model, with BMD being the outcome variable, and TT and E2 predictor variables. Because both BMD and concentration of E2 or TT change with age and weight, the analysis was adjusted for the effects of age and body mass index (BMI). Because the distribution of E2 and TT was not normally distributed, we transformed the variables into natural logarithmic scale before analysis. The statistical significance of each predictor variable was assessed by the t-test after adjusting for all other variables in the model. A nominal $P$ value of 0.05 was considered "statistical significance". The coefficient of determination $\left(\mathrm{R}^{2}\right)$ from the most optimal model was obtained and further analyzed. In order to address the relative importance of each and combined predictors, we used the "lmg" method [15] to decompose the overall $\mathrm{R}^{2}$ into individual effect. The $R$ program was used for the statistical analysis [16] and the package relaimpo within $R$ 
package [17] was used to estimate the relative contribution of individual predictor variable.

\section{Results}

The study involved 205 men and 432 women, aged between 18 and 87 years (Table 1). The average age among men was 44 , which was slightly lower than that among women (48 years). Fifty-one percent of men and $0.7 \%$ of women reported being current smokers. Approximately $20 \%$ men and $13 \%$ women were obese (body mass index greater than $25 \mathrm{~kg} / \mathrm{m}^{2}$ ). On average, men had significantly lower E2 and higher TT concentrations than women. The mean value of TT was $487 \mathrm{pg} / \mathrm{mL}$ in men and $20 \mathrm{pg} / \mathrm{mL}$ in women; and that of E2 was $28 \mathrm{pg} / \mathrm{mL}$ and $80 \mathrm{pg} / \mathrm{mL}$ in men and women, respectively.

\section{Sex hormones and age}

The relationship between E2 and age in women was described by the third-degree polynomial regression model (Figure 1). As expected, serum levels of estradiol remained stable between the ages of 18 and 35, followed by a rapid decrease between the age of 40 and 60 . There was no noticeable change in estradiol between the age of 60 and 70 years. In contrast, the serum levels of estradiol in men declined gradually with advancing age, but the magnitude of decline was modest, with $0.8 \%$ per year.

The relationship between age and total testosterone was also different between sexes. In men, there was no appreciable change in TT with advancing age. However, in women, there was a linear decline of total testosterone levels with advancing age, with the rate of decrease being $2.5 \%$ per year.

\section{Sex hormones and BMD}

In univariate analysis, individuals with higher serum levels of E2 also had higher BMD at the femoral neck and lumbar spine in both men and women (Figure 2). There was no appreciable association between total testosterone and BMD in men, but a positive relationship was observed in women.

For a given age and body weight, men with greater serum levels of estradiol had greater BMD at the femoral

Table 1 Characteristics of 205 men and $\mathbf{4 3 2}$ women

\begin{tabular}{lccc}
\hline Variable & Men & Women & P-value \\
\hline $\mathrm{N}$ & 205 & 432 & \\
Age $(\mathrm{yr})$ & $43.8(18.4)$ & $47.7(17.1)$ & 0.009 \\
Weight $(\mathrm{kg})$ & $61.1(9.2)$ & $52.2(7.6)$ & $<0.0001$ \\
Height $(\mathrm{cm})$ & $164.2(6.6)$ & $153.4(5.3)$ & $<0.0001$ \\
Body mass index $\left(\mathrm{kg} / \mathrm{m}^{2}\right)$ & $22.7(3.2)$ & $22.2(3.0)$ & 0.091 \\
Current smoking & $105(51 \%)$ & $3(0.7 \%)$ & $<0.0001$ \\
Testosterone $(\mathrm{pg} / \mathrm{mL})$ & $487(208)$ & $20(32)$ & $<0.0001$ \\
Estradiol $(\mathrm{pg} / \mathrm{mL})$ & $28(42)$ & $80(237)$ & $<0.0001$ \\
\hline
\end{tabular}

Note: Data are shown in mean and standard deviation (in bracket). neck and lumbar spine (Table 2). In the presence of estradiol, total testosterone was not a significant predictor of BMD in men. In women, estradiol but not total testosterone was a significant predictor of BMD. The magnitude of association between estradiol and BMD in men was comparable with (in the case of lumbar spine BMD) or greater than that (femoral neck BMD) in women. Each standard deviation lower in log estradiol was associated with $0.032 \mathrm{~g} / \mathrm{cm}^{2}$ lower in femoral neck BMD in men; the estimate for women was $0.014 \mathrm{~g} / \mathrm{cm}^{2}$.

\section{Analysis of relative importance}

Relative importance analysis (Table 3) shows that variation in serum levels of estradiol "explained" 2.5\% (95\% CI 0.4 to $7.8 \%$ ) of variance in femoral neck BMD. However, in women, the relative contribution of estradiol to BMD variation was even greater: $11.3 \%$ (95\% CI 8.1 to $15.3 \%$ ) for femoral neck BMD and $11.7 \%$ (95\% CI 8.5 to $15.9 \%$ ) for lumbar spine BMD. In women, the relative contribution of estradiol to BMD variation was even greater than the contribution of body weight.

\section{Discussion}

The traditional view of sex hormones and bone health is that estrogens are the main sex steroids affecting bone maturation in women, and that androgens are the corresponding sex steroids in men. However, this view has been challenged by an initial case report [3] and subsequent reports $[4,5]$ which showed that the "female hormone" is actually important for bone mineralization and bone growth in men. However, such a relationship has not been well documented in Asian men, and it is not clear of the magnitude of effect of estrogen in bone mass in men. The present study on Asian men shows that estrogen, not testosterone, was an independent determinant of bone density. However, the contribution of estrogen to the variance of bone density in men is likely to be modest.

Our finding of positive association between estradiol and bone mass in men is largely consistent with previous studies in Caucasian men. Indeed, several observational studies in older Caucasian men have shown that circulating free estrogen or total estradiol, not testosterone, was associated with bone density [18-20] and bone loss [14,21-23]. Our finding is also in line with a recent observation that in Chinese men, low levels of bioavailable E2 were associated with low bone density and greater bone loss [24]. Our results further show that the magnitude of association between estradiol and BMD in men was comparable with or greater than that in women. Collectively, the present data and evidence to date support the conjecture that estradiol is probably more important than testosterone as a determinant of bone growth and bone maintenance in men and women alike. 

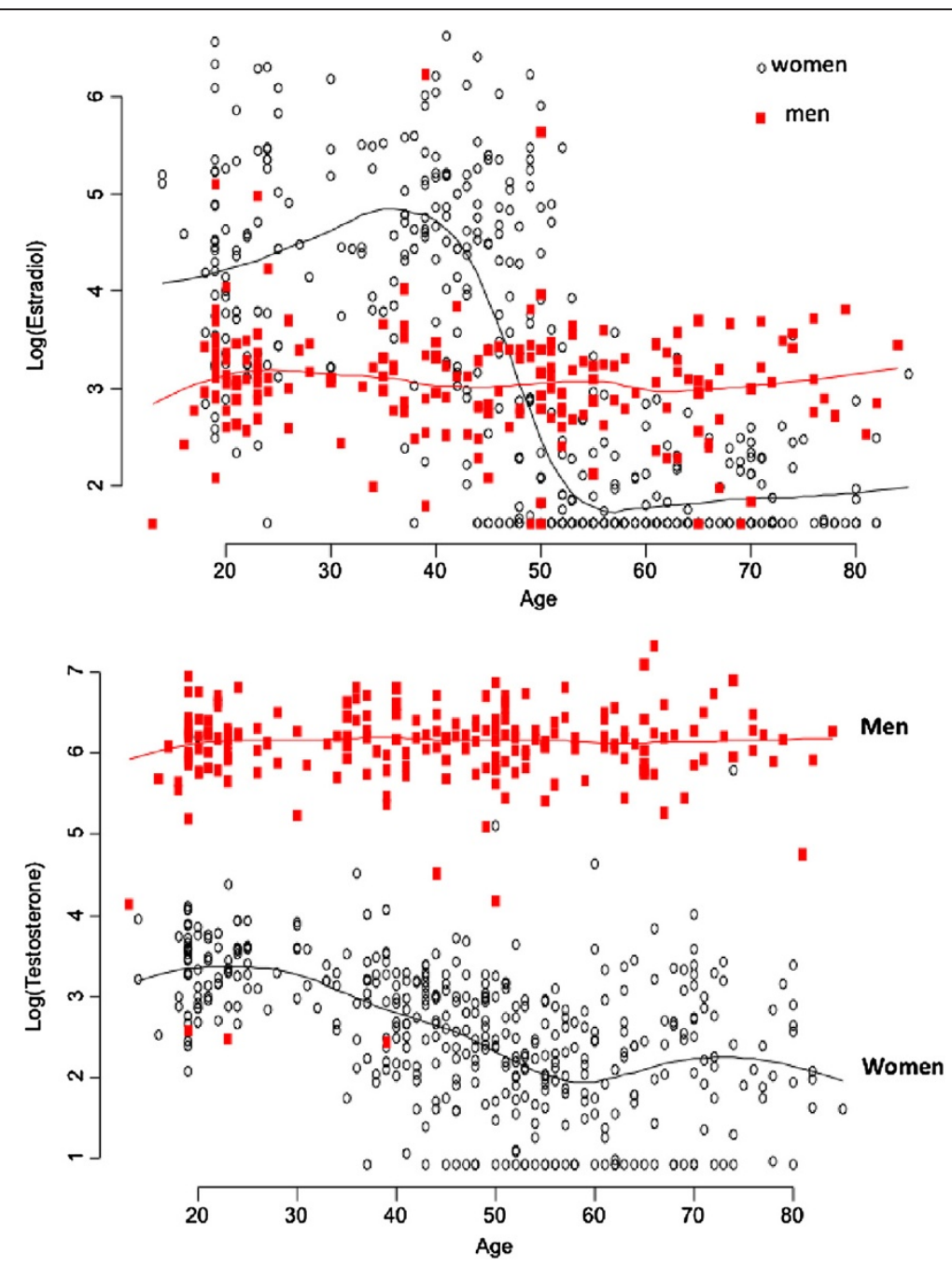

Figure 1 Association between estradiol (upper panel) and testosterone (below panel) with age in men (red) and women (black).

The mechanism of effect of estrogen on bone is well known. Deficiency of estrogen leads to an increased osteoclastic formation, expanding the remodeling space, increased cortical porosity, and enlarged the resorption area on trabecular surface $[25,26]$. The net result of these effects is bone loss. Indeed, estrogen deficiency is associated with an increased in bone resorption marker in men [14] and women [27]. Moreover, treatment of elderly men with an aromatase inhibitor resulted in increased bone resorption and decreased bone formation [28]. Treating osteoporotic men with selective estrogen receptor modulator increased femoral neck BMD [29]. Taken together, these studies suggest that estrogen is causally linked to bone mass in men, and that estrogen might be more important for bone health than are declining levels of testosterone.

However, it can not rule out the role of androgens in maintaining skeletal integrity and bone homeostasis in men. Testosterone contributes to the initiation of bone resorption and maintenance of bone formation. Moreover, the majority of estrogens in elderly men is derived from androgens by peripheral conversion [30]. The gene involved in the conversion is the CYP19A1 gene. Men with TTTA repeats in the gene had higher estradiol levels and reduced bone loss than those with lower number of such repeats [31].

Despite the established relationship between estrogen and bone density in men, the magnitude of this association has not been quantified. In this study, by using a sophisticated statistical technique, we were able to estimate that estradiol explained only 1.2 to $2.5 \%$ of between-individual variation in BMD. The upper estimate of attributable proportion was $\sim 8 \%$. This relative attribution was much lower than body weight which accounted for $20 \%$ of variation in BMD. Most of the association between body weight and BMD is due to muscle mass [32,33]. The dominant contribution of body weight and modest attribution of estrogen imply that in men physical fitness may be more important than sex hormones as a factor for maintaining bone mass in the old age. 


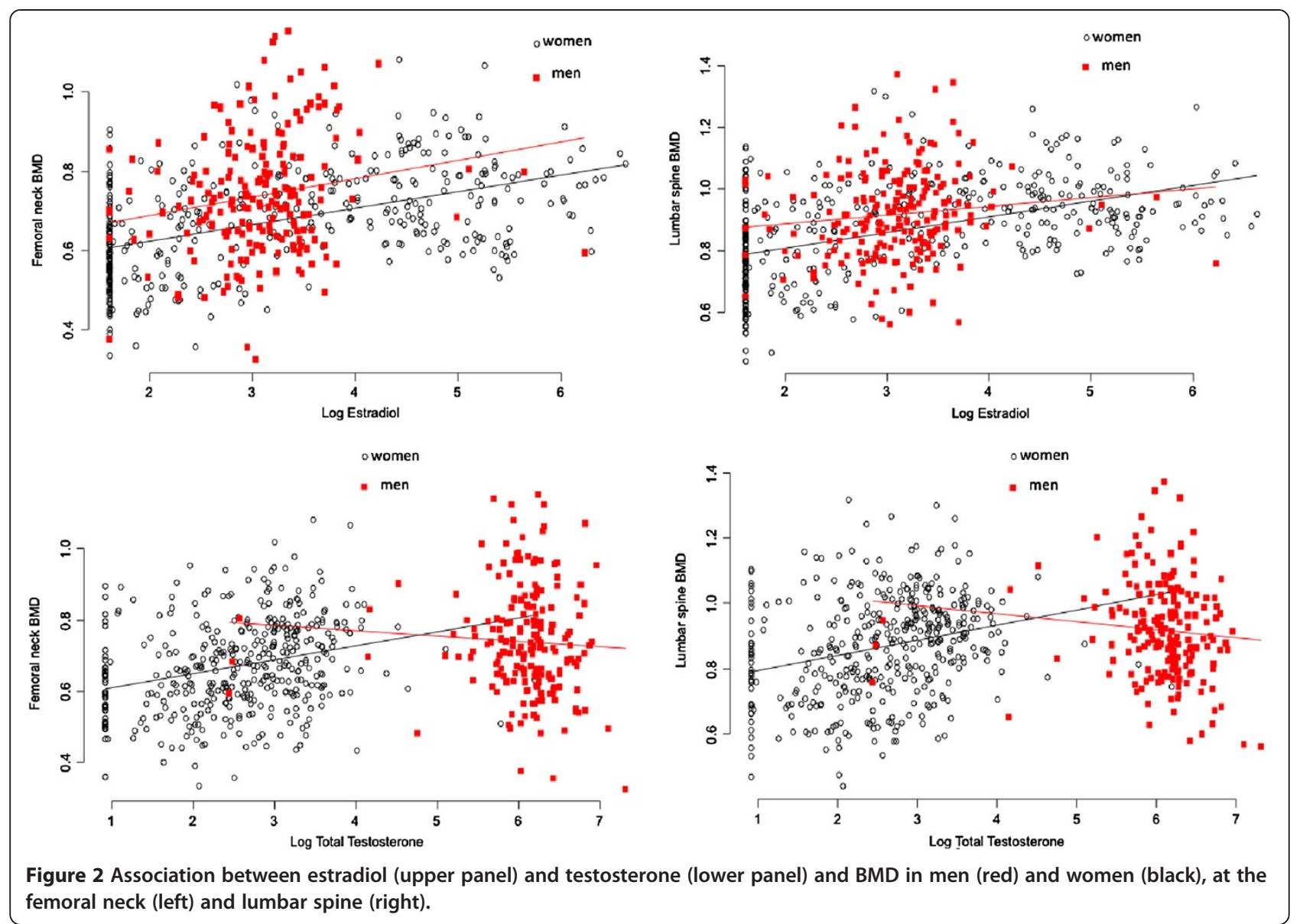

Table 2 Association between sex hormones and bone mineral density: the linear regression model

\begin{tabular}{|c|c|c|c|c|}
\hline \multirow[t]{2}{*}{ Variable } & \multicolumn{2}{|c|}{ Men } & \multicolumn{2}{|c|}{ Women } \\
\hline & Coeffcient (SE) & P-value & Coeffcient (SE) & P-value \\
\hline \multicolumn{5}{|l|}{ Femoral neck BMD } \\
\hline Intercept & $0.097(0.105)$ & 0.354 & $0.443(0.032)$ & $<0.0001$ \\
\hline Age & $-1.152(0.104)$ & $<0.0001$ & $-1.483(0.121)$ & $<0.0001$ \\
\hline Age squared & $0.023(0.101)$ & 0.820 & $-0.268(0.096)$ & 0.005 \\
\hline Weight & $0.07(0.0008)$ & $<0.0001$ & $0.004(0.0008)$ & $<0.0001$ \\
\hline Log (testosterone) & $0.020(0.012)$ & 0.090 & $-0.004(0.0005)$ & 0.530 \\
\hline Log (estradiol) & $0.032(0.120)$ & 0.008 & $0.014(0.004)$ & 0.001 \\
\hline \multicolumn{5}{|l|}{ Lumbar spine BMD } \\
\hline Intercept & $0.411(0.131)$ & 0.002 & $0.554(0.040)$ & $<0.0001$ \\
\hline Age & $-0.293(0.130)$ & 0.025 & $-1.360(0.150)$ & $<0.0001$ \\
\hline Age squared & $-0.253(0.127)$ & 0.048 & $-0.765(0.119)$ & $<0.0001$ \\
\hline Weight & $0.007(0.001)$ & $<0.0001$ & $0.004(0.0006)$ & $<0.0001$ \\
\hline Log (testosterone) & $-0.001(0.015)$ & 0.951 & $0.006(0.008)$ & 0.401 \\
\hline Log (estradiol) & $0.026(0.015)$ & 0.086 & $0.021(0.005)$ & $<0.0001$ \\
\hline
\end{tabular}

Note: $\mathrm{SE}$, standard error. 
Table 3 Relative contribution of age, body weight, testosterone, and estradiol levels to variation in bone mineral density at the femoral neck and lumbar spine

\begin{tabular}{lccccc}
\hline Predictor & \multicolumn{2}{c}{ Men } & & \multicolumn{2}{c}{ Women } \\
\cline { 2 - 5 } & Femoral neck BMD & Lumbar spine BMD & & Femoral neck BMD & Lumbar spine BMD \\
\hline Age & 0.331 & 0.035 & 0.279 & 0.194 \\
Weight & $(0.246-0.409)$ & $(0.01-0.09)$ & $(0.227-0.331)$ & $(0.155-0.239)$ \\
& 0.202 & 0.204 & 0.065 & 0.067 & $(0.032-0.136)$ \\
Log (testosterone) & $(0.125-0.276)$ & $(0.120-0.294)$ & $0.036-0.114)$ & 0.031 \\
& 0.003 & 0.005 & 0.029 & $(0.017-0.054)$ \\
Log (estradiol) & $(0.001-0.044)$ & $(0.001-0.056)$ & $0.017-0.051)$ & 0.117 \\
& 0.025 & 0.012 & 0.113 & $(0.081-0.153)$ & $(0.085-0.159)$ \\
\hline
\end{tabular}

Note: The data are shown in percentage and 95\% confidence interval in brackets. For example, age accounted for $33.1 \%$ of the variation in femoral neck BMD in men. In the presence of age, weight, and testosterone, estradiol further accounted for $2.5 \%$ of the variation in femoral neck BMD.

In our study, serum levels of testosterone in men remained fairly stable while there was a linear decline of estradiol levels with advancing age in men with modest magnitude of decrease. We found perhaps not surprising that the age-related decrease in estradiol levels in women was greater than that in men, such that before the age of 50 , estradiol concentrations in women was higher than that in men, but after the age of 50 years, estradiol levels in women was lower than in men. This finding is consistent with previous studies [21,34-37].

The present results should be interpreted within a number of potential strengths and weaknesses. The study participants were randomly drawn from the general population which should enhance the findings' external validity. The DXA measurement of BMD is considered gold accurate and reliable, which ensure the study's internal validity. Moreover, the technique of measurement of estradiol and testosterone was based on the novel Elecsys automated assay, which has been shown to be a precise method for measuring sex hormones over a wide reportable range in serum. Indeed, recent studies have shown that measurement of estradiol and testosterone by this method was highly concordant with the liquid chromatography tandem mass spectrometry methods [38-40]. Nevertheless, we did not measure SHBG, free estradiol and free testosterone in the study. The study was designed as a cross-sectional investigation, and as a result, no causal inferences could be made for the observed relationships between estradiol and bone density. In this study we did not ascertain the phase of menstrual cycle which could affect the measured value of estradiol within an individual. However, the intra-invididual variability was statistically considered as a component of the random error in the multiple linear regression model.

\section{Conclusion}

In summary, these data suggest that estradiol, but not testosterone, was a significant determinant of bone mineral density in Asian men and women. However, the relative contributions of estradiol to the between-individual variation in bone density is likely to be modest for men. This finding is consistent with the hypothesis that estrogen is a key hormone in the skeletal maturation, bone mineralization and maintenance of bone mass in men and women. The finding also provides further supportive evidence for the "unitary model" of pathogenesis of osteoporosis [22].

Competing interests

The authors declare that they have no competing interests.

\section{Authors' contributions}

Contributions of the authors to the manuscript included Study concept and design: LH-P and TVN; Acquisition of data: LH-P. Analysis and interpretation of data: LH-P, NDN, and TN; Drafting the manuscript: LH-P, TVN and NDN; Data analysis: NDN and TVN; Critical revision of the manuscript: LH-P, TVN and NDN. All authors read and approved the final manuscript.

\section{Acknowledgments}

The study was partially supported by a grant from the University Commission for Development (CUD) program, Belgium, and the Department of Science and Technology, Ho Chi Minh City. Professor T. V. Nguyen is supported by a senior research fellowship from the Australian National Health and Medical Research Council. We thank the following friends and colleagues for their support and help in the recruitment and providing logistic support for the study: Fr. Pham Ba Lam, Fr. Vu Minh Danh, Mr. Pham Doan Phong, Mr. Luong Thang Phat, Mr. Nguyen Cong Phu, and Mr. Tien Ngoc Tuan. We thank Dr. Le Thi Ngoc Linh, Dr. Pham Ngoc Khanh of the People's Hospital 115; and our medical students Nguyen Thi Thanh Mai, Nguyen Hai Dang, Vo thi Thuy An, Nguyen thi Thanh Thao, Mai Duy Linh, Nguyen Vu Dat, Diem Dang Khoa, and Tran Hong Bao for their assistance in the interview of participants. The authors thank Professor Lesley V. Campbel of the Garvan Institute of Medical Research for her critical reading of the manuscript and great comments that led to the current version.

\section{Author details}

'Department of Internal Medicine, Pham Ngoc Thach University of Medicine, Thanh Thai Street, District 10, Ho Chi Minh City, Vietnam. ${ }^{2}$ Department of Rheumatology, People's Hospital 115, Ho Chi Minh City, Vietnam. ${ }^{3}$ Osteoporosis and Bone Biology Program, Garvan Institute of Medical Research, Sydney, Australia. ${ }^{4}$ St Vincent's Clinical School, Faculty of Medicine, University of New South Wales, Sydney, Australia. ${ }^{5}$ Bone and Muscle Research Unit, Ton Duc Thang University, Ho Chi Minh City, Vietnam. 
Received: 20 August 2013 Accepted: 18 December 2013

Published: 23 December 2013

\section{References}

1. Ettinger B, Pressman A, Sklarin P, Bauer DC, Cauley JA, Cummings SR: Associations between low levels of serum estradiol, bone density, and fractures among elderly women: the study of osteoporotic fractures. J Clin Endocrinol Metab 1998, 83(7):2239-2243.

2. Barrett-Connor E, Stuenkel CA: Hormone replacement therapy (HRT)-risks and benefits. Int J Epidemiol 2001, 30(3):423-426.

3. Smith EP, Boyd J, Frank GR, Takahashi H, Cohen RM, Specker B, Williams TC, Lubahn DB, Korach KS: Estrogen resistance caused by a mutation in the estrogen-receptor gene in a man. N Engl J Med 1994, 331(16):1056-1061.

4. Carani C, Qin K, Simoni M, Faustini-Fustini M, Serpente S, Boyd J, Korach KS, Simpson ER: Effect of testosterone and estradiol in a man with aromatase deficiency. N Engl J Med 1997, 337(2):91-95.

5. Morishima A, Grumbach MM, Simpson ER, Fisher C, Qin K: Aromatase deficiency in male and female siblings caused by a novel mutation and the physiological role of estrogens. J Clin Endocrinol Metab 1995, 80(12):3689-3698

6. Bilezikian JP, Morishima A, Bell J, Grumbach MM: Increased bone mass as a result of estrogen therapy in a man with aromatase deficiency. N Engl J Med 1998, 339(9):599-603.

7. Rochira V, Faustini-Fustini M, Balestrieri A, Carani C: Estrogen replacement therapy in a man with congenital aromatase deficiency: effects of different doses of transdermal estradiol on bone mineral density and hormonal parameters. J Clin Endocrinol Metab 2000, 85(5):1841-1845.

8. Center JR, Nguyen TV, Sambrook PN, Eisman JA: Hormonal and biochemical parameters in the determination of osteoporosis in elderly men. J Clin Endocrinol Metab 1999, 84(10):3626-3635.

9. Khosla S, Melton $\sqcup$ 3rd, Atkinson EJ, O'Fallon WM: Relationship of serum sex steroid levels to longitudinal changes in bone density in young versus elderly men. J Clin Endocrinol Metab 2001, 86(8):3555-3561.

10. Greendale GA, Edelstein S, Barrett-Connor E: Endogenous sex steroids and bone mineral density in older women and men: the Rancho Bernardo Study. J Bone Miner Res 1997, 12(11):1833-1843.

11. Ongphiphadhanakul B, Rajatanavin R, Chanprasertyothin S, Piaseu N, Chailurkit L: Serum oestradiol and oestrogen-receptor gene polymorphism are associated with bone mineral density independently of serum testosterone in normal males. Clin Endocrinol (Oxf) 1998, 49(6):803-809.

12. Slemenda CW, Longcope C, Zhou L, Hui SL, Peacock M, Johnston CC: Sex steroids and bone mass in older men. Positive associations with serum estrogens and negative associations with androgens. J Clin Invest 1997, 100(7):1755-1759.

13. Amin S, Zhang Y, Sawin CT, Evans SR, Hannan MT, Kiel DP, Wilson PW, Felson DT: Association of hypogonadism and estradiol levels with bone mineral density in elderly men from the Framingham study. Ann Intern Med 2000, 133(12):951-963.

14. Falahati-Nini A, Riggs BL, Atkinson EJ, O'Fallon WM, Eastell R, Khosla S: Relative contributions of testosterone and estrogen in regulating bone resorption and formation in normal elderly men. J Clin Invest 2000, 106(12):1553-1560.

15. Grömping U: Estimators of relative importance in linear regression based on variance decomposition. Amer Statistician 2007, 61:139-147.

16. R Development Core Team: R: A Language and Environment for Statistical Computing. 270th edition. Vienna, Austria: R Foundation for Statistical Computing; 2008. URL:http://www.R-project.org.

17. Gromping U: Relative Importance for Linear Regression in R: the Package relaimpo. J Statist Software 2006, 17(1):1-27.

18. Bouillon R, Bex M, Vanderschueren D, Boonen S: Estrogens are essential for male pubertal periosteal bone expansion. J Clin Endocrinol Metab 2004, 89(12):6025-6029.

19. Mellstrom $\mathrm{D}$, Johnell $\mathrm{O}$, Ljunggren $\mathrm{O}$, Eriksson $\mathrm{AL}$, Lorentzon $\mathrm{M}$, Mallmin $\mathrm{H}$, Holmberg A, Redlund-Johnell I, Orwoll E, Ohlsson C: Free testosterone is an independent predictor of BMD and prevalent fractures in elderly men: MrOS Sweden. J Bone Miner Res 2006, 21(4):529-535.

20. Araujo AB, Travison TG, Leder BZ, McKinlay JB: Correlations between serum testosterone, estradiol, and sex hormone-binding globulin and bone mineral density in a diverse sample of men. J Clin Endocrinol Metab 2008, 93(6):2135-2141.
21. Khosla S, Melton $\sqcup$ 3rd, Atkinson EJ, O'Fallon WM, Klee GG, Riggs BL: Relationship of serum sex steroid levels and bone turnover markers with bone mineral density in men and women: a key role for bioavailable estrogen. J Clin Endocrinol Metab 1998, 83(7):2266-2274.

22. Riggs BL, Khosla S, Melton LJ 3rd: A unitary model for involutional osteoporosis: estrogen deficiency causes both type I and type II osteoporosis in postmenopausal women and contributes to bone loss in aging men. J Bone Miner Res 1998, 13(5):763-773.

23. Szulc P, Munoz F, Claustrat B, Garnero P, Marchand F, Duboeuf F, Delmas PD: Bioavailable estradiol may be an important determinant of osteoporosis in men: the MINOS study. J Clin Endocrinol Metab 2001, 86(1):192-199.

24. Woo J, Kwok T, Leung JC, Ohlsson C, Vandenput L, Leung PC: Sex steroids and bone health in older Chinese men. Osteoporos Int 2012, 23(5):1553-1562.

25. Eriksen EF, Langdahl B, Vesterby A, Rungby J, Kassem M: Hormone replacement therapy prevents osteoclastic hyperactivity: a histomorphometric study in early postmenopausal women. J Bone Miner Res 1999, 14(7):1217-1221.

26. Riggs BL, Khosla S, Melton $L J$ 3rd: Sex steroids and the construction and conservation of the adult skeleton. Endocr Rev 2002, 23(3):279-302.

27. McKane WR, Khosla S, Risteli J, Robins SP, Muhs JM, Riggs BL: Role of estrogen deficiency in pathogenesis of secondary hyperparathyroidism and increased bone resorption in elderly women. Proc Assoc Am Physicians 1997, 109(2):174-180.

28. Taxel P, Kennedy DG, Fall PM, Willard AK, Clive JM, Raisz LG: The effect of aromatase inhibition on sex steroids, gonadotropins, and markers of bone turnover in older men. J Clin Endocrinol Metab 2001, 86(6):2869-2874.

29. Smith MR, Fallon MA, Lee $H$, Finkelstein JS: Raloxifene to prevent gonadotropin-releasing hormone agonist-induced bone loss in men with prostate cancer: a randomized controlled trial. J Clin Endocrinol Metab 2004, 89(8):3841-3846.

30. Kaufman JM, Vermeulen A: The decline of androgen levels in elderly men and its clinical and therapeutic implications. Endocr Rev 2005, 26(6):833-876.

31. Gennari L, Masi L, Merlotti D, Picariello L, Falchetti A, Tanini A, Mavilia C, Del Monte F, Gonnelli S, Lucani B, et al: A polymorphic CYP19 TTA repeat influences aromatase activity and estrogen levels in elderly men: effects on bone metabolism. J Clin Endocrinol Metab 2004, 89(6):2803-2810.

32. Wang MC, Bachrach LK, Van Loan M, Hudes M, Flegal KM, Crawford PB: The relative contributions of lean tissue mass and fat mass to bone density in young women. Bone 2005, 37(4):474-481.

33. Ho-Pham LT, Nguyen ND, Lai TQ, Nguyen TV: Contributions of lean mass and fat mass to bone mineral density: a study in postmenopausal women. BMC Musculoskelet Disord 2010, 11:59

34. Woo J, Kwok T, Leung JCS, Ohlsson C, Vandenput L, Leung PC: Sex steroids and bone health in older Chinese men. Osteoporos Int 2011. Epub ahead of print.

35. Ferrini RL, Barrett-Connor E: Sex hormones and age: a cross-sectional study of testosterone and estradiol and their bioavailable fractions in community-dwelling men. Am J Epidemio/ 1998, 147(8):750-754.

36. Yeap BB, Alfonso H, Chubb SA, Handelsman DJ, Hankey GJ, Norman PE, Flicker $\mathrm{L}$ : Reference ranges and determinants of testosterone, dihydrotestosterone, and estradiol levels measured using liquid chromatography-tandem mass spectrometry in a population-based cohort of older men. J Clin Endocrinol Metab 2012, 97(11):4030-4039.

37. Orwoll E, Lambert LC, Marshall LM, Phipps K, Blank J, Barrett-Connor E, Cauley J, Ensrud K, Cummings S: Testosterone and estradiol among older men. J Clin Endocrinol Metab 2006, 91(4):1336-1344.

38. Rosner WHS, Sluss PM, Vesper HW, Wierman ME: Challenges to the measurement of estradiol: an endocrine society position statement. J Clin Endocrinol Metab 2013. Epub ahead of print.

39. Gislefoss RE, Grimsrud TK, Hoie K, Morkrid L: Stability of testosterone measured in male archival serum samples by two different methods. Scand J Clin Lab Invest 2012, 72(7):555-562.

40. Wang C, Catlin DH, Demers LM, Starcevic B, Swerdloff RS: Measurement of total serum testosterone in adult men: comparison of current laboratory methods versus liquid chromatography-tandem mass spectrometry. J Clin Endocrinol Metab 2004, 89(2):534-543.

doi:10.1186/1471-2474-14-366

Cite this article as: Ho-Pham et al:: Quantification of the relative contribution of estrogen to bone mineral density in men and women. BMC Musculoskeletal Disorders 2013 14:366 